\title{
World Vitiligo Day Campaign
}

Yan Valle*

CEO Vitiligo Research Foundation

*Corresponding author: Yan Valle, CEO Vitiligo Research Foundation, 1, Penn Plaza, \#6205, New York, NY 10119, USA, Tel: +1-646-327-8169; E-mail: yan@vrfoundation.org

Received: May 28, 2014, Accepted: June 2, 2014, Published date: June 5, 2014,

Copyright: (c) 2014 Valle Y, This is an open-access article distributed under the terms of the Creative Commons Attribution License, which permits unrestricted use, distribution, and reproduction in any medium, provided the original author and source are credited.

\section{Letter}

Journal of Pigmentary Disorders, OMICS Group

Prof. Torello Lotti, MD, MD (Hon)

Editor-in-Chief

May 28, 2014

Dear Editor-in-Chief,

This Letter to Editor seeks to update doctors, healthcare professionals, insurers and payers, health ministries, philanthropic institutions, vitiligo patients and their families on the World Vitiligo Day campaign.

Vitiligo is a serious, immune-mediated, non-contagious, neglected disease, with unknown triggers, under-investigated mechanism and unpredictable manifestation. Despite the dearth of medications available to treat psoriasis-a disease with similar prevalence numbers and impact on quality of life - vitiligo has no known cure or specific treatments. Few therapies can reduce or stop vitiligo symptoms for prolonged periods of time, but no single treatment works for everyone. Worse, not all of these medicines have been approved in all countries.

Mounting data show that it is critical that the active stage of vitiligo be diagnosed and managed early, within first 6 weeks of disease manifestation. Unfortunately, new patients get trapped between physicians, dermatologists, insurance companies and their daily activities, and typically lose this best window of opportunity. As a result, vitiligo quickly progresses and has an overwhelming impact on the patient's life, causing severe mental trauma and often leading to depression, alcoholism, self-isolation and thoughts of suicide.

The overall humanitarian, social and economic costs of vitiligo are immense. Vitiligo has severe psychological and socioeconomic burdens on nearly 100 million people, or up to $1.5 \%$ of the worldwide population, equally affecting all races and social groups. Developing countries bear the greatest economic burden due to the risk for misdiagnosis of the disease, little-to-no access to effective treatments, widespread stigmatization and discrimination.
VR Foundation strives on a daily basis for recognition of vitiligo by global leaders, national health authorities and insurance providers in the United States and worldwide. With support from the community, our 501(c) 3 non-profit foundation conducts the World Vitiligo Day campaign that seeks to mark every June 25 as a global day of observance, and to portray the true nature of vitiligo, to raise awareness and to eradicate common myths and misconceptions about the disease. In small but effective steps, this campaign will help lift the heavy burden of vitiligo worldwide and improve quality of life of millions of people.

World Vitiligo Day campaign focuses on raising awareness, communication with the mass-media and advocacy to health ministries. The headquarters of the campaign that started in 2011 have moved across the globe: from Nigeria to Italy to United States and, finally, to India this year. Our goal is to collect half a million petitions in order to address the United Nations on behalf of the global vitiligo community. We have collected over 482,892 signatures before today.

Patient organizations alone do not have the scope to mobilize significant support and attention to vitiligo. Together, we (doctors, researchers and support groups) can help vitiligo patients to recognize their own disease, and to seek proper and urgent treatment.

The breadth, severity and complexity of the disease require international collaboration in therapy development. Our collective effort will facilitate the research community to develop new treatments, and medical community to properly treat the disease.

Help us get this neglected disease on agenda of the UN, the world's top international organization that has the power and influence to make a positive change in the lives of those suffering from vitiligo. We invite readers of the Journal of Pigmentary Disorders to go to website www.25June.org and sign the petition. Then, sign up for the newsletter with latest news on vitiligo and World Vitiligo Day campaign at www.VRFoundation.org Mark 25 June by hosting open educational events for your vitiligo patients and their families.

Sincerely Yours,

Yan Valle 